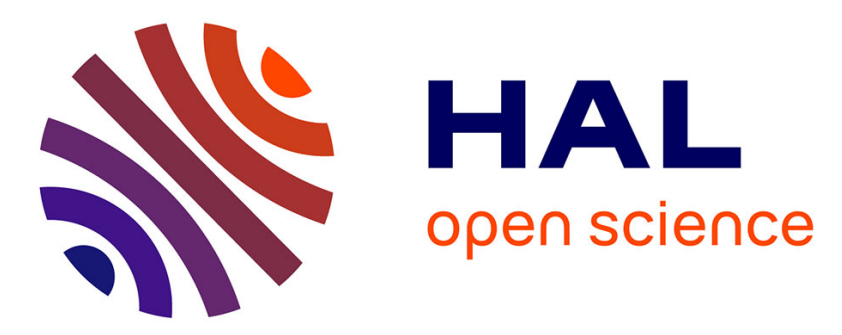

\title{
Light-mediated chiroptical switching of an achiral foldamer host in presence of a carbohydrate guest
}

Susnata Pramanik, Brice Kauffmann, Stefan Hecht, Yann Ferrand, Ivan Huc

\section{To cite this version:}

Susnata Pramanik, Brice Kauffmann, Stefan Hecht, Yann Ferrand, Ivan Huc. Light-mediated chiroptical switching of an achiral foldamer host in presence of a carbohydrate guest. Chemical Communications, 2021, 57 (1), pp.93-96. 10.1039/d0cc06484j . hal-03402677

\section{HAL Id: hal-03402677 \\ https://hal.science/hal-03402677}

Submitted on 29 Oct 2021

HAL is a multi-disciplinary open access archive for the deposit and dissemination of scientific research documents, whether they are published or not. The documents may come from teaching and research institutions in France or abroad, or from public or private research centers.
L'archive ouverte pluridisciplinaire HAL, est destinée au dépôt et à la diffusion de documents scientifiques de niveau recherche, publiés ou non, émanant des établissements d'enseignement et de recherche français ou étrangers, des laboratoires publics ou privés. 


\title{
Light-mediated chiroptical switching of an achiral foldamer host in presence of a carbohydrate guest
}

\author{
Susnata Pramanik, ${ }^{a}$ Brice Kauffmann, ${ }^{\mathrm{b}}$ Stefan Hecht,,${ }^{\mathrm{c}, \mathrm{d}, \mathrm{e}}$ Yann Ferrand, ${ }^{\mathrm{f}}$ Ivan Huc*a
}

\begin{abstract}
A photoresponsive diarylethene was incorporated in an achiral helical foldamer container. A carbohydrate guest was found to induce opposite handedness upon binding to the open and closed forms of the diarylethene-containing foldamer, thus enabling chiroptical switching of an achiral host mediated by a chiral guest.
\end{abstract}

Chiroptical switches are molecules that can change their interaction with polarized light in response to an external reversible stimulus such as the interaction with a guest or a metal ion, a change in redox state, $\mathrm{pH}$, solvent, temperature or pressure; a transition between solid and solution state; or the action of light itself. ${ }^{1}$ Helical chirality has often been exploited in chiroptical switches because molecular helicity tends to be strongly reflected in chiroptical properties. Thus, a helix may amplify the effect of a chiral stimulus that occurs at a single stereogenic centre acting as a strong helix handedness inducer. ${ }^{2}$ Conversely, when each monomer of a helical polymer bears a stereogenic center, helix handedness may be strongly biased by a cumulative effect even though the contribution of each chiral monomer is minute, and therefore responsive to minor changes of the environment. ${ }^{3}$ In light-controlled chiroptical switches, the light stimulus generally operates on the chiral entity itself, directly causing the appearance, disappearance, or inversion of a helix handedness bias. ${ }^{4}$ In contrast, we introduce here a chiroptical switch where a light trigger acts on an achiral helical receptor. The light-induced transition results in a relatively modest local conformational change. This subtle change, however, reverts the way the achiral foldamer receptor interacts with the same chiral guest, eventually leading to a considerable conformational and chiroptical response.

a. Department Pharmazie and Center for Integrated Protein Science, LudwigMaximilians-Universität, Butenandtstr. 5-13, 81377 München (Germany), E-mail: ivan.huc@cup.Imu.de.

b. Université de Bordeaux CNRS, INSERM, UMS3033, Institut Européen de Chimie et Biologie (IECB), 2 rue Robert Escarpit, 33600 Pessac (France).

c. Department of Chemistry \& IRIS Adlershof, Humboldt-Universität zu Berlin, BrookTaylor-Str. 2, 12489 Berlin (Germany).

d. DWI-Leibniz Institute for Interactive Materials, Forckenbeckstr. 50, 52074 Aachen (Germany).

e. Institute of Technical and Macromolecular Chemistry, RWTH Aachen University, Worringer Weg 2, 52074 Aachen (Germany).

f. CBMN (UMR5248), Univ. Bordeaux-CNRS-IPB, Institut Européen de Chimie et Biologie, 2 rue Robert Escarpit, 33600 Pessac (France).
$\mathrm{We}^{5}$ and others ${ }^{6}$ have developed aromatic helical foldamers as potent receptors for saccharides in organic solvents. In the case of aromatic foldamer capsules, ${ }^{5,7}$ i.e. helical containers that completely surround their substrate and seclude it from the solvent, high substrate selectivity has often been observed. Here, selectivity encompasses guest selectivity (among different saccharides), diastereoselectivity (with respect to helix handedness), and anomer and tautomer selectivity (among the different forms of a given saccharide). For example, the $P$ helical conformer of achiral sequence 3 (Fig. 1b) has high affinity of $\beta$ D-fructo-pyranose.5a Thus, when D-fructose is added to $\mathbf{3}, P$ helicity is induced almost quantitatively, resulting in an intense CD signal.

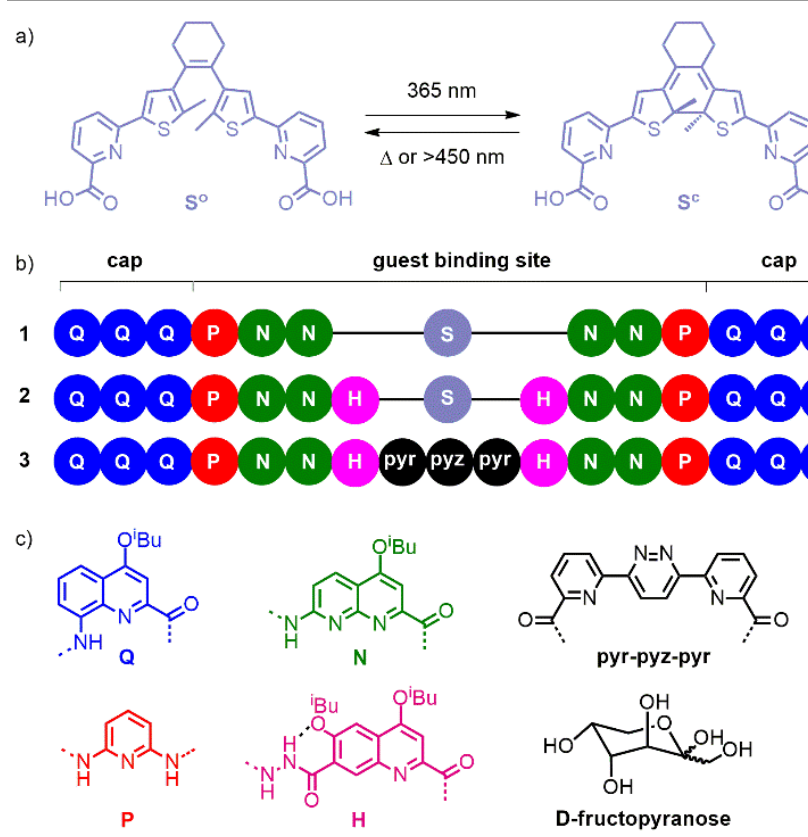

Figure 1. a) Light-induced switching of diarylethene $\mathbf{S}$ between the open $\left(\mathbf{S}^{\circ}\right)$ and closed (Sc) forms. b) Oligoamide sequences. Terminal $\mathbf{Q}$ units have an 8-nitro group instead of an 8-amino function. c) Chemical structures of the individual units and guest. 

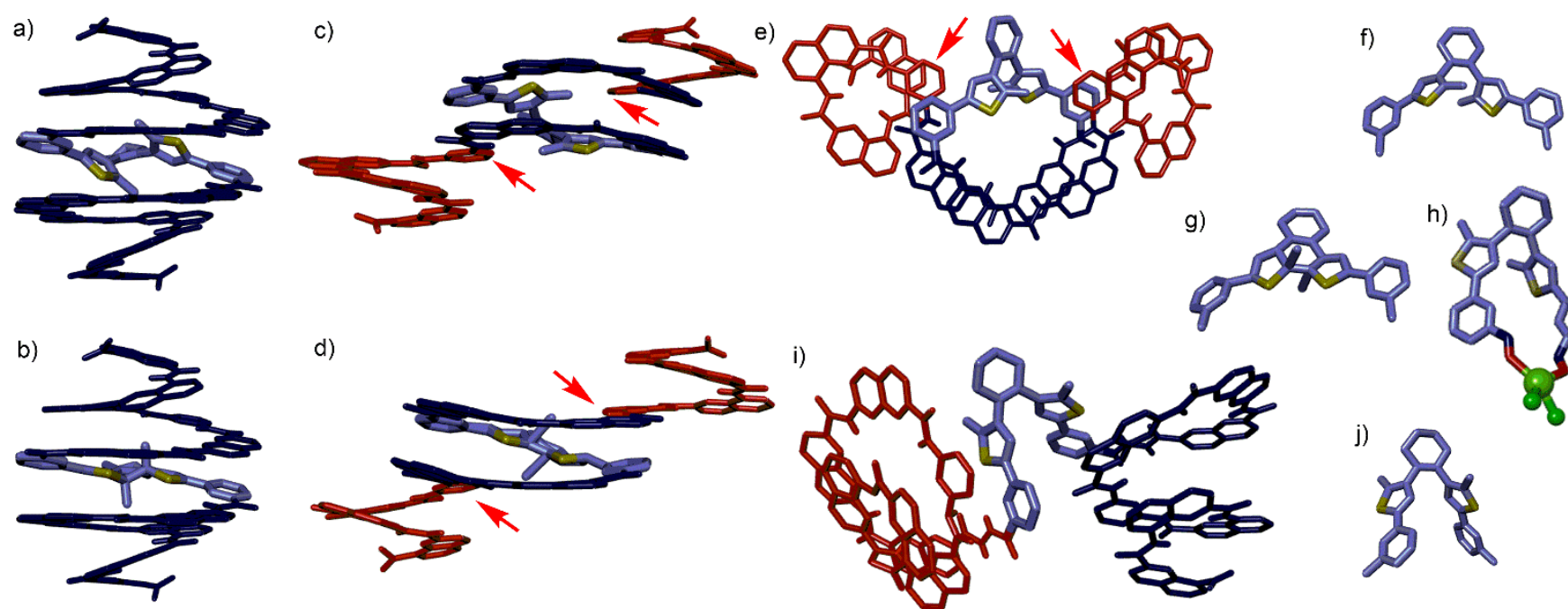

Figure 2. Energy minimised capsule conformations of a) $\mathbf{1}^{\mathbf{0}}$ and b) $\mathbf{1}^{\mathrm{c}}$. Single crystal structures of $\mathbf{1}(\mathrm{c}-\mathrm{h})$ and $\mathbf{2}(\mathrm{i}-\mathrm{j})$. c) side view, e) top views and f) isolated $\mathbf{S}$ unit of the structure of $\mathbf{1}^{\circ}$. d) side view and $\mathbf{g}$ ) isolated $\mathbf{S}$ unit of the structure of $\mathbf{1}^{\mathrm{c}}$. Note that the stereochemistry of $\mathbf{S}^{\mathbf{c}}$ is opposite in d) and in b). $\mathbf{h}$ ) Isolated $\mathbf{S}$ unit complexed to $\mathbf{M g C l} 2$ in a crystal structure of $\mathbf{1}^{\circ} \mathrm{S} \mathrm{MgCl}_{2}$ (Fig. S24) The $\mathbf{M g}^{2+}$ ion coordinates the carbonyl oxygen atoms of $\mathbf{S}$ unit). I) side view and j) isolated $\mathbf{S}$ unit of the crystal structure of $\mathbf{2}^{\circ}$. Red and dark blue segments indicate $M$ and $P$ helices, respectively. $\mathbf{S}$ unit are shown in blue-grey, sulphur atoms are shown in yellow. Red arrows indicate monomers where helix handedness inversion occurs.

We devised that this high selectivity offers opportunities for switching and endeavoured to introduce a photo-responsive unit in these capsule sequences. Our initial idea was not to implement a large photo-induced conformational change that could mediate guest capture and release. Instead, we initially thought that triggering a small structural change with light would alter selectivity in such a way that it may allow for the replacement of a saccharide guest by another. Diarylethenes are good examples of photoswitches where the photo-induced conformational change is both modest and well-defined. ${ }^{8}$ We therefore designed and synthesized unit "S" (Figure 1a), a diarylethene functionalized with pyridinecarboxylic acid units for its incorporation in an oligoamide foldamer sequence (see ESI for details on the synthesis).

$\mathbf{Q}_{3} \mathbf{P} \mathbf{N}_{2}$ and $\mathbf{Q}_{3} \mathbf{P} \mathbf{N}_{2} \mathbf{H}$ were chosen as common segments of foldamer sequences that selectively recognize organic acids, e.g. D-/L-tartaric acid, ${ }^{9}$ or saccharides, ${ }^{5 a}$ respectively. The UV-Vis absorption spectra of these segments overlap with that of the dimethyl ester of $\mathbf{S}$ (Fig. S1). At $365 \mathrm{~nm}$, MeO-S-OMe $\left(\varepsilon_{365}=\right.$ $\left.2700 \mathrm{M}^{-1} \mathrm{~cm}^{-1}\right)$ absorbs 6 to 8 times less than $\mathbf{Q}_{3} \mathbf{P N}_{2}-\operatorname{Boc}\left(\varepsilon_{365}=\right.$ $\left.16800 \mathrm{M}^{-1} \mathrm{~cm}^{-1}\right)$ and $\mathbf{Q}_{3} \mathbf{P N}_{2} \mathrm{H}-\mathrm{Boc}\left(\varepsilon_{365}=20800 \mathrm{M}^{-1} \mathrm{~cm}^{-1}\right)$. Thus, a significant amounts of photons will be lost upon irradiating $\mathbf{S}$ within an aromatic foldamer sequence at this wavelength. Nevertheless, ${ }_{1} \mathrm{H}$ NMR spectra of $\mathbf{Q}_{3} \mathbf{P N}_{2}-$ Boc and $\mathbf{Q}_{3} \mathbf{P} \mathbf{N}_{2}$ recorded after irradiation at $365 \mathrm{~nm}$ in $\mathrm{CDCl}_{3}$ (Fig. S2) show no photodegradation, thus indicating their compatibility with the excitation of an $\mathbf{S}$ unit.

Sequence 1 was designed as a prototype. Energy minimized molecular models (MacroModel, MMFFs force field) of the $\mathbf{S}^{\circ}$ and $\mathbf{S}^{\mathbf{c}}$ forms of $\mathbf{1}$ suggested that the overall capsule conformation would not change much upon ring closure of the diarylethene (Fig2a,b). In both forms, the methyl substituents of the thiophene rings protrude in the helix cavity, albeit at different orientations. Of note is the formation of two diasterogenic centers upon ring closure, whose stereochemistry may or may not relate to the handedness of the flanking helix segments.

Light-induced switching between $\mathbf{1}^{\circ}$ and $1^{c}$ was probed by UV-Vis spectroscopy. A $10 \mu \mathrm{M}$ solution of $\mathbf{1}^{\text {o }}$ in $5 / 95$ DMSO: $\mathrm{CHCl}_{3}$ vol/vol was irradiated at $365 \mathrm{~nm}$ until no change in the absorption spectrum was observed. A new band characteristic of $\mathbf{S}^{\mathbf{c}}$ emerged at $592 \mathrm{~nm}$, which resulted in an intense colour change from light yellow to deep purple. The reverse toggling was achieved using light at $\lambda>450 \mathrm{~nm}$. Nevertheless, successive switching cycles accomplished by repeating light irradiation led to some fatigue, i.e. a decrease of band intensity apparently due to intramolecular side reactions (Fig. S7).

Crystal structures of $\mathbf{1}$ and $\mathbf{2}$ provided important structural information. Upon attempting to crystallize $\mathbf{1}^{\mathbf{c}}$, co-crystals in which $1^{\mathrm{c}}$ and $\mathbf{1}^{\circ}$ overlapped in a 30:70 ratio were eventually obtained. ${ }^{\ddagger}$ The two structures are shown separately in Fig. 2c-g. Their overlapping in the crystal lattice is consistent with their similar shapes and with crystal-to-crystal transformations of other diarylethenes. ${ }^{10, \S}$ However, the structures show not a capsule conformation but a central $\mathbf{N}_{\mathbf{2}} \mathbf{S} \mathbf{N}_{\mathbf{2}}$ helix and two $\mathbf{Q}_{\mathbf{3}} \mathbf{P}$ segments flipped outwards. Such flipping has been recently observed in related compounds ${ }^{11}$ and may reflect an imperfect fit of the $\mathbf{S}$ unit within the capsule shape. Furthermore, a crystal structure of $\mathbf{1}^{\circ}$ was obtained incidentally containing a $\mathrm{Mg}^{2+}$ ion (Fig. 2h, Fig. S24). ${ }^{*}$ Though the ion certainly biases the conformation, the fact that the $\mathbf{S}$ unit in this structure is found in the parallel conformation, unable to undergo ring closure (Fig. 2h), further suggests larger conformational freedom of $\mathbf{1}$ than we had anticipated.

Circular dichroism (CD) and NMR titrations of 1 with tartaric acid in 5/95 DMSO: $\mathrm{CDCl}_{3}$ vol/vol revealed no binding, perhaps because the methyl groups of $\mathbf{S}$ interfere with the accessibility of the $\mathbf{Q}_{\mathbf{3}} \mathbf{P} \mathbf{N}_{\mathbf{2}}$ segments for hydrogen bonding. We thus turned to longer sequence $\mathbf{2}$ which we expected to possess a larger inner cavity (see ESI for detailed synthesis). Single crystals of $2^{\circ}$ 
suitable for X-ray diffraction were obtained ${ }^{\ddagger}$ and revealed yet another conformation of the $\mathbf{S}$ unit (Fig. 2j), with the two $\mathbf{Q}_{3} \mathbf{P N}_{2} \mathbf{H}$ segments positioned as two independent hemicapsules (Fig. 2i). In the crystal lattice, one of these segments is intertwined in a double helix with a neighbouring molecule (Fig. S25). Such aggregation appears not to be significant in solution (Figs. S3-S4). Nevertheless, the multiple conformations observed in the solid state and the sharp NMR spectra together point to a significant flexibility of the $\mathbf{S}$ unit and to rapid dynamics in solution.

Reversible light-induced switching between $2^{\circ}$ and $\mathbf{2}^{\mathrm{c}}$ was similar to that observed with 1 (Fig. S8). Monitoring ring closure by ${ }^{1} \mathrm{H}$ NMR revealed a photostationary state (PSS) at $365 \mathrm{~nm}$ consisting of a 25/75 $\mathbf{2}^{\mathbf{o}}: \mathbf{2}^{\mathbf{c}}$ ratio. Upon irradiation with wavelengths $\lambda>450 \mathrm{~nm}$, the PSS reverted to a $98 / 22^{\circ}: 2^{\mathrm{c}}$ ratio within minutes (Fig. S5). Due to the analogy between sequences $\mathbf{2}$ and $\mathbf{3}$, we assessed binding of fructose to $\mathbf{2}$. As an initial test, 25 equiv. of $D$-fructose were added to a solution of $2^{\circ}$ in $5 \%$ DMSO in $\mathrm{CHCl}_{3}$. The $\mathrm{CD}$ spectra showed the slow emergence of an intense negative band at $360 \mathrm{~nm}$, i.e. the induction of an $M$ helix opposite to earlier observations with 3.5a Handedness induction was shown to plateau after $4.5 \mathrm{~h}$ (Fig. S9). The titration data could be fitted to a $1: 1$ binding isotherm $\left(K_{\mathrm{a}}=7.7\right.$ $10^{4} \mathrm{M}^{-1}$, Fig. 3a,b, Fig. S10) and molecular modelling suggested that fructose could fit in the capsule-like conformation of $\mathbf{2}$ (Fig. S22). ${ }^{1} \mathrm{H}$ NMR titrations revealed that host-guest binding is fast on the NMR timescale (Fig. S12-13), even at low temperature (Fig. S14-15), and causes modest $(<0.2 \mathrm{ppm})$ chemical shifts variations. This result contrasts with earlier observations, e.g. with 3, which showed slow exchange of the binding of organic guests in foldamer capsules. ${ }^{5,9}$ Fast exchange with $\mathbf{2}$ may result from the flexibility of the central $\mathbf{S}$ unit revealed by solid state investigations (Fig. 2). It is remarkable that the flexibility of the receptor does not hamper the diastereoselectivity highlighted by the high $\Delta \varepsilon$ values.

The $\mathbf{2}^{\mathrm{c}} / \mathbf{2}^{\circ}$ mixture at the PSS was then titrated with $\mathrm{D}$ fructose. $C D$ demonstrated an even more intense, but negative, band at $364 \mathrm{~nm}$ (Fig. 3c), highlighting the induction of $P$ handedness. Thus, $\mathbf{2}^{\mathrm{c}}$ binds fructose as well but with a diastereoselectivity inverse to that of $2^{\circ}$. The CD band is intense despite the fact that part of it is cancelled by the presence of $25 \% \mathbf{2}^{\circ}$ at the PSS. Molecular models suggest that fructose does not fit as well in the cavity of the capsule form of $\mathbf{2}^{\mathrm{c}}$ (Fig. S22) since ring closure orients the methyl groups such that they occupy part of the space. Thus, binding geometries of $2^{\circ}$ and $2^{\circ}$ differ. One should consider that, in these experiments, $2^{c}$ was produced in the absence of any chiral material and thus itself exists as a racemic mixture of $\mathbf{S}^{\mathbf{c}}$ enantiomers, regardless of the handedness of the flanking helices. The titration data show a slightly sigmoidal curve that could be fitted to a 1:1 binding isotherm $\left(K_{\mathrm{a}}=8.710^{3} \mathrm{M}^{-1}\right.$, Fig. 3d, Fig. S11) taking into consideration the presence of $2^{\circ}$. Note that the model used did not consider the possibility that the two diastereomers of $\mathbf{2}^{\mathrm{c}}$ may not bind the same to fructose. $C D$ titrations sum up all binding events and may not allow for this level of accuracy. ${ }^{1} \mathrm{H}$ NMR titrations of $2^{c}$ were hampered by broad signals (Fig. S19). The reciprocal effect of complex formation on the fructose anomeric and furanose/pyranose equilibria was not investigated.
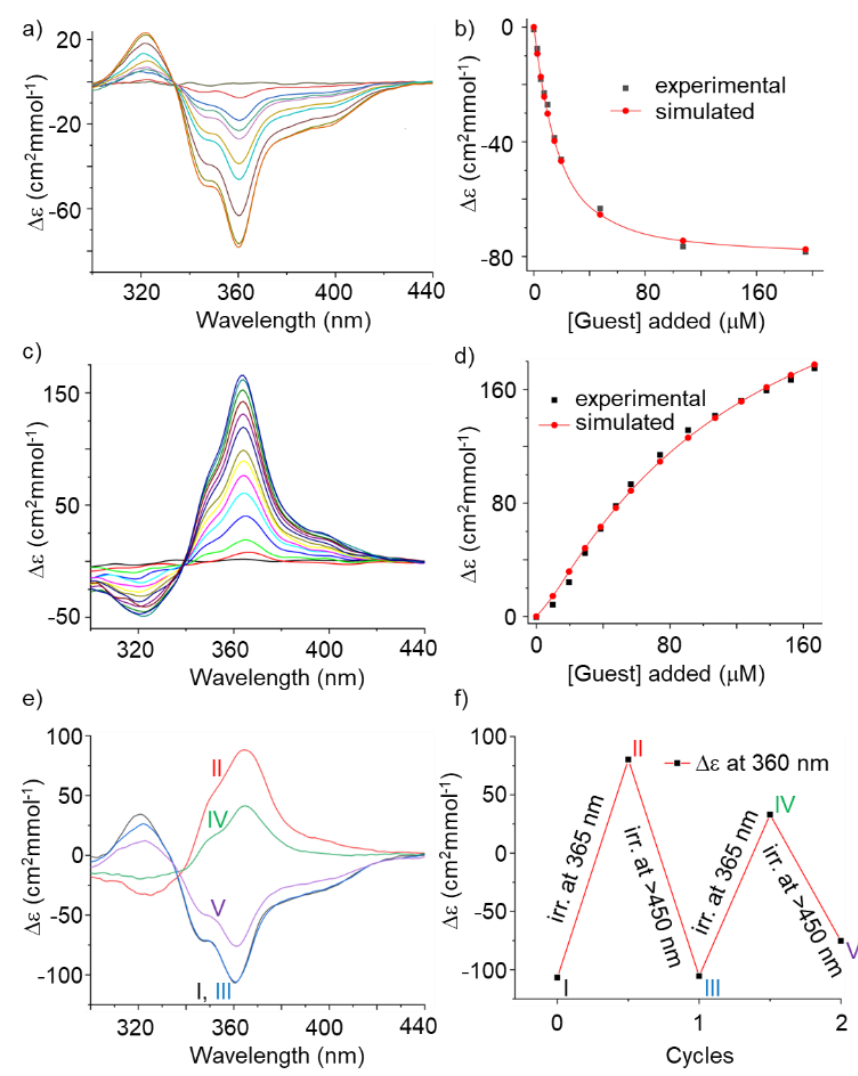

Figure 3. Induced CD spectra upon binding of D-fructose by a) $2^{\circ}$ and c) $2^{c}\left(\right.$ at $10^{-5} \mathrm{M}$ ) in $5 \% \mathrm{DMSO}$ in $\mathrm{CHCl}_{3}$. Curve-fitting of binding isotherms b) of a), and d) of c). e) $\mathrm{CD}$ spectra (10\% DMSO in $\mathrm{CHCl}_{3}$, at $\left.10 \mu \mathrm{M}\right)$ and $\mathrm{f}$ ) induced $\mathrm{CD}$ changes at $360 \mathrm{~nm}$ depicting chiroptical switching of $\mathbf{2} \supset \mathrm{D}$-fructose using reversible light irradiation.

The opposite binding diastereoselectivity of achiral $2^{\circ}$ and $\mathbf{2}^{\mathrm{c}}$, and the intense $C D$ bands, suggest that their light-induced interconversion in presence of fructose may work as a chiroptical switch having the intriguing and novel feature that $2^{\circ}$ is achiral. A $10 \mu \mathrm{M}$ solution of $\mathbf{2}^{\circ}$ in $5 \%$ DMSO in $\mathrm{CHCl}_{3}$ was treated with 25 equiv. of D-fructose to reach saturation and induce $M$ handedness, and then irradiated with $365 \mathrm{~nm}$ light. The inversion of the CD band was observed (Fig. S17) albeit with a reduction of intensity of $47 \%$ compared to that obtained when irradiating first and subsequently adding the sugar (Fig. S16). The reason for this behaviour is not fully understood yet. Perhaps the presence of the sugar induces conformations less favourable to cyclization, eventually leading to a PSS where the proportion of $\mathbf{S}^{\mathbf{c}}$ is smaller. The larger proportion of $2^{\circ}$ would then partly cancel the induced $C D$ resulting from $2^{c}$. Broad NMR spectra did not allow to ascertain this (Fig. S19). In these experiments, irradiation is performed after fructose addition and induction of helix handedness. A chirality transfer from the helices to an axial chirality of $S^{\circ}$ that would result in an enrichment of one enantiomer of $\mathbf{S}^{\mathbf{c}}$ is in principle possible. Such transfer has been observed in other systems. ${ }^{12}$ However, we found no trace of such a transfer, i.e. no CD band above $500 \mathrm{~nm}$ that would surely belong to Sc (Fig. S18). 
When trying to switch the $\mathbf{2}^{\mathrm{c}} \supset$ fructose complex back to the $\mathbf{2}^{\circ} \rightarrow$ fructose complex using visible light, very slow kinetics of handedness reversal were observed. These experiments were then repeated in $10 \%$ DMSO (instead of $5 \%$ ) in $\mathrm{CHCl}_{3}$ and excess fructose. DMSO was expected to accelerate helix inversion kinetics and to also alter sugar binding. Indeed, in this case, shining alternatively $365 \mathrm{~nm}$ light and $>450 \mathrm{~nm}$ light allowed for a back and forth switching between a prevalence of $P$ helices and a prevalence of $M$ helices (Fig. 3e,f). The system nevertheless showed some fatigue, possibly due to the photoinstability of the capsule itself after prolonged light exposure.

Despite some obvious imperfections such as slow kinetics and fatigue, achiral oligomer $\mathbf{2}$ demonstrates chiroptical switching behaviour in the presence of fructose. This behaviour can be accounted for by the fact that small structural changes in the foldamer structure lead to drastic changes in sugar binding selectivity. Other sequences that show a similar behaviour have already been found in our laboratories and will be reported elsewhere. The photo-induced reversal of guest enantiomer binding opens up capabilities in various areas such as switchable asymmetric catalysis and chiral guest swapping. For example, upon locking the handedness of $\mathbf{Q} 3 \mathbf{P N}_{2} \mathbf{H}$ segments with chiral groups, ${ }^{5 a}$ successively shining UV and visible light in presence of racemic fructose would lead to the capture of one enantiomer and the release of the other. Upon shining light on part of a solution, one might then produce a $\mathbf{2}^{\mathrm{c}} / \mathbf{2}^{\circ}$ gradient that would generate a gradient of enantiomers, i.e. a physical separation of enantiomers by light.

We thank Dr. Pedro Mateus for assistance with the fitting of titration data and Dr. Arundhati Roy for assistance with irradiation experiments.

\section{Notes and references}

¥ Single co-crystals suitable for $\mathrm{x}$-ray diffraction analysis were obtained by slow liquid-liquid diffusion. 1c/10 (CCDC \#2032748); $1^{\circ} \supset \mathrm{MgCl}_{2}$ (CCDC \#2032749), $2^{\circ}$ (CCDC \#2032750). See the ESI for details about crystallographic methods and data.

$\S$ Because of the notorious fragility of foldamer crystals, crystalto-crystal transformations with $\mathbf{1}$ or $\mathbf{2}$ were not attempted.

1 (a) H. Goto and E. Yashima, J. Am. Chem. Soc., 2002, 124, 7943-7949; (b) T. Muraoka, K. Kinbara and T. Aida, Nature, 2006, 440, 512-515; (c) B. L. Feringa, R. A. van Delden, N. Koumura, and E. M. Geertsema, Chem. Rev., 2000, 100, 1789-1816; (d) K. Kinbara, T. Muraokaa and T. Aida, Org. Biomol. Chem., 2008, 6, 1871-1876; (e) J. W. Canary, Chem. Soc. Rev., 2009, 38, 747-756; (f) H. lida, T. Mizoguchi, S.-D. Oh and E. Yashima, Polym. Chem., 2010, 1, 841-848; (g) J. W. Canary, S. Mortezaei and J Liang, Coord. Chem. Rev., 2010, 254, 2249-2266; (h) B. L. Feringa and W. R. Browne, Molecular Switches, 2nd Ed., Wiley-VCH, Weinheim, 2011; (i) Z. Dai, J. Lee and W. Zhang, Molecules, 2012, 17, 1247-1277; (j) H. Isla and J. Crassous, C. R. Chimie, 2016, 19, 39-49; (k) S. Kawabata, N. Ousaka and E. Yashima, Chem. Commun., 2018, 54, 2417-2420; (I) J. Zhang, Y. Zhou, Y. Yao, Z. Cheng, T. Gao, H. Li and P. Yan, J. Mater. Chem. C, 2020, 8, 6788-6796.

2 (a) C. Dolain, V. Maurizot and I. Huc, Angew. Chem. Int. Ed., 2003, 42, 2737-2740; (b) H. Jiang, C. Dolain, J.-M. Léger, H. Gornitzka and I. Huc, J. Am. Chem. Soc., 2004, 126, 10341035.
3 (a) T. Nakano and Y. Okamoto, Chem. Rev., 2001, 101, 40134038; (b) J. J. L. M. Cornelissen, A. E. Rowan, R. J. M. Nolte and N. A. J. M. Sommerdijk, Chem. Rev., 2001, 101, 40394070; (c) E. Yashima, K. Maeda and Y. Furusho, Acc. Chem. Res., 2008, 41, 1166-1180; (d) K. Akagi, Chem. Rev., 2009, 109, 5354-5401; (e) E. Yashima, K. Maeda, H. lida, Y. Furusho and K. Nagai, Chem. Rev., 2009, 109, 6102-6211.

4 (a) K. Uchida, M. Walko, J. J. D. de Jong, S. Sukata, S. Kobatake, A. Meetsma, J. van Esch and B. L. Feringa, Org. Biomol. Chem., 2006, 4, 1002-1006; (b) Y. Tani, T. Ubukata, Y. Yokoyama and Y. Yokoyama, J. Org. Chem., 2007, 72, 1639-1644; (c) T. Hirose, M. Irie and K. Matsuda, New J. Chem., 2009, 33, 1332-1334; (d) W. Li, X. Li, Y. Xie, Y. Wu, M. Li, X.-Y. Wu, W.-H. Zhu and H. Tian, Sci. Rep., 2015, 5, 9186; (e) T. Nakagawa, T. Ubukata and Y. Yokoyama, J. Photochem. Photobiol. C, 2018, 34, 152-191; (f) D. Roke, S. J. Wezenberg, and B. L. Feringa, Proc. Natl. Acad. Sci. USA, 2018, 115, 94239431; (g) C. Jurissek, F. Berger, F. Eisenreich, M. Kathan and S. Hecht, Angew. Chem. Int. Ed., 2019, 58, 1945-1949.

5 (a) N. Chandramouli, Y. Ferrand, G. Lautrette, B. Kauffmann, C. D. Mackereth, M. Laguerre, D. Dubreuil, and I. Huc, Nat. Chem., 2015, 7, 334-341; (b) P. Mateus, B. Wicher, Y. Ferrand and I. Huc, Chem. Commun., 2018, 54, 5078-5081; (c) S. Saha, B. Kauffmann, Y. Ferrand and I. Huc, Angew. Chem. Int. Ed., 2018, 57, 13542-13546; (d) P. Mateus, N. Chandramouli, C. D. Mackereth, B. Kauffmann, Y. Ferrand and I. Huc, Angew. Chem. Int. Ed., 2020, 59, 5797-5805.

6 (a) M. Waki, H. Abe and M. Inouye, Angew. Chem. Int. Ed., 2007, 46, 3059-3061; (b) H. Abe, H. Machiguchi, S. Matsumoto and M. Inouye, J. Org. Chem., 2008, 73, 46504661; (c) J. Y. Hwang, H.-G. Jeon, Y. R. Choi, J. Kim, P. Kang, S. Lee and K.-S. Jeong, Org. Lett., 2017, 19, 5625-5628.

7 Y. Ferrand and I. Huc, Acc. Chem. Res., 2018, 51, 970-977.

8 M. Irie, T. Fukaminato, K. Matsuda and S. Kobatake, Chem. Rev., 2014, 114, 12174-12277.

9 Y. Ferrand, A. M. Kendhale, B. Kauffmann, A. Grélard, C. Marie, V. Blot, M. Pipelier, D. Dubreuil, and I. Huc, J. Am. Chem. Soc., 2010, 132, 7858-7859.

10 M. Morimoto and Masahiro Irie, Chem. Commun., 2005, 3895-3905.

11 B. Gole, B. Kauffmann, V. Maurizot, I. Huc and Y. Ferrand, Angew. Chem. Int. Ed., 2019, 58, 8063-8067.

12 (a) T. Yamaguchi, K. Uchida and M. Irie, J. Am. Chem. Soc. 1997, 119, 6066-6071; (b) M. Fredersdorf, R. Göstl, A. Kolmer, V. Schmidts, P. Monecke, S. Hecht and C. M. Thiele, Chem. Eur. J. 2015, 21, 14545-14554.; (c) C. Jurissek, F. Berger, F. Eisenreich, M. Kathan and S. Hecht, Angew. Chem. Int. Ed. 2019, 58, 1945-1949. 